\title{
LEVANTAMENTO DOS DISPOSITIVOS DE DRENAGEM URBANA DO MUNICÍPIO DE RIACHO FRIO-PI
}

\author{
Tainá Damasceno Melo, Kássia Hellem Tavares da Silva*, \\ Elisângela Pereira de Sousa*, Jeandra Pereira dos Santos*, \\ Israel Lobato Rocha*
}

\begin{abstract}
RESUMO: Para a expansão dos aglomerados urbanos, é necessária a retirada da cobertura vegetal para pavimentação de ruas, construções e edificações, ocasionando em sérios impactos ambientais, como a impermeabilização do solo que minimiza a infiltração e aumenta o escoamento superficial, e assim, a população fica sujeita a possíveis riscos de inundações. Neste contexto, é necessário um sistema de drenagem bem projetado, para evitar possíveis transtornos e melhorar as condições estruturais da cidade bem como melhoria de vida da população. Desta forma, este trabalho teve como objetivo fazer o levantamento dos dispositivos do sistema de drenagem urbana do município de Riacho frio-PI, analisando as condições estruturais, disposição, deficiência e eficiências dos mesmos e propor medidas de controle. Para execução deste trabalho foi feito um levantamento de campo, com visita no local, utilizando câmara fotográfica, GPS, material para anotações e posteriormente identificar os dispositivos do sistema de drenagem analisando os possíveis problemas com os mesmos. Após o levantamento de campo foi possível identificar que o município de Riacho Frio possui deficiência na quantidade e condições sanitárias dos dispositivos de drenagem, pois em toda a cidade apenas 2 ruas possuem bocas-de-lobo e galerias de águas pluviais. Constatou também, a presença de resíduos nas galerias e bocas-de-lobo podendo ocorrer o entupimento e comprometer o funcionamento das mesmas, bem como o lançamento de efluentes na rede de drenagem motivo explicado pela falta de tratamento de esgoto e conhecimento da população.
\end{abstract}

PALAVRAS-CHAVE: Impermeabilização, Inundações, Planejamento urbano, Saneamento.

ABSTRACT: For the expansion of urban areas, it is necessary to remove the vegetation for paving streets, buildings and buildings, resulting in serious environmental impacts such as soil sealing that reduces infiltration and increases runoff, and thus the population is subject to possible risks of flooding. In this context, a drainage system and designed it is necessary to avoid possible disorders and improving the structural conditions of the city and improvement of people's living. Thus, this study aimed to survey the devices of the urban drainage system of the city of Riacho Frio-PI, analyzing the structural conditions, disposition, disability and efficiencies thereof and propose control measures. For the implementation of this work was made a field survey, with on-site visit, using camera, GPS, material for notes and later identify the drainage system devices analyzing the possible problems with them. After the field survey it was possible to identify the Riacho Frio municipality has low and poor sanitary conditions of drainage devices because throughout the city just 2 streets have mouths-of-wolf and storm sewer. It also found the presence of residues in galleries and mouths-of-wolf may occur clogging and compromising their operation and the effluent discharge to sewer reason explained by the lack of sewage treatment and knowledge of the population.

KEYWORDS: waterproofing, Flooding, urban planning, Sanitation.

\footnotetext{
*Acadêmicas do curso de Tecnologia em Gestão Ambiental. Instituto Federal do Piauí - Campus Corrente. E-mail: taina_melo10@hotmail.com;

**Professor do Instituto Federal do Piauí - Campus Corrente.
} 


\section{INTRODUÇÃO}

A ocupação do espaço urbano, sem o planejamento adequado, tem como consequências alterações no funcionamento dos sistemas de drenagem, gerando grandes transtornos para a sociedade e para o meio ambiente. Um dos principais problemas relacionados com a infraestrutura e urbanização segundo Tucci (2005) é a grande concentração populacional em pequena área, com deficiência no sistema de transporte, falta de abastecimento e saneamento, ar e água poluído, além das inundações.

Para a expansão dos aglomerados urbanos, é necessária a retirada da cobertura vegetal para pavimentação de ruas, construções e edificações, ocasionando em sérios impactos ambientais, como a impermeabilização do solo que minimiza a infiltração e aumenta o escoamento superficial, e assim, a população fica sujeita a possíveis riscos de inundações.

O Manual de Drenagem urbana (2002) afirma que "estes impactos têm deteriorado a qualidade de vida da população, através do aumento da frequência e do nível das inundações, redução da qualidade de água e aumento de materiais sólidos nos corpos receptores". Neste contexto, é necessário um sistema de drenagem bem projetado, para evitar possíveis transtornos e melhorar as condições estruturais da cidade bem como melhoria de vida da população.

O sistema de drenagem urbana é composto pelo micro drenagem e macrodrenagem onde, o principal objetivo desses sistemas, segundo Santos (2007), é afastar rapidamente as aguas das áreas urbanas, para garantir o funcionamento adequado do sistema de transporte urbano e dos serviços essenciais da cidade durante a chuva.

De acordo com o manual de Drenagem da Prefeitura de São Paulo (2012) o sistema de drenagem inicial ou de micro drenagem compreende o pavimento das ruas, guias, bocas-de-lobo, sarjetas e galerias de águas pluviais de menor porte. A macrodrenagem é constituída pelos córregos, ribeirões ou rios que cortam as cidades, recolhendo as aguas provenientes de todo o sistema de micro drenagem das bacias urbanas (SANTOS, 2007).

O manual de drenagem da prefeitura de São Paulo (2012) argumenta que "o sistema de drenagem urbana faz parte do conjunto de melhoramentos públicos existentes em uma área urbana, quais sejam: redes de abastecimento de água, de coleta de esgotos sanitários”, etc. Ainda segundo o manual, é conveniente para a comunidade que a área urbana seja planejada de forma integrada, isto é, que todos os melhoramentos públicos sejam planejados coerentemente.

Desta forma, este trabalho teve como objetivo fazer o levantamento dos dispositivos do sistema de drenagem urbana do município de Riacho frio-PI, analisando as condições estruturais, disposição, deficiência e eficiências dos mesmos e propor medidas de controle. 


\section{MATERIAL E MÉTODOS}

\section{1 Área de estudo}

O estudo foi realizado no município de Riacho frio (PI) localizado na Microrregião das Chapadas do Extremo Sul Piauiense, possuindo uma área de 2.221,950 km² e população urbana de 2.222 habitantes, correspondendo a 52\% da população total (4.241 habitantes) no município (IBGE, 2010). A sede do município possui as coordenadas geográficas de $10^{\circ} 07^{\prime} 31^{\prime \prime}$ de latitude sul e 44 57'09”' de longitude oeste (Figura 1).

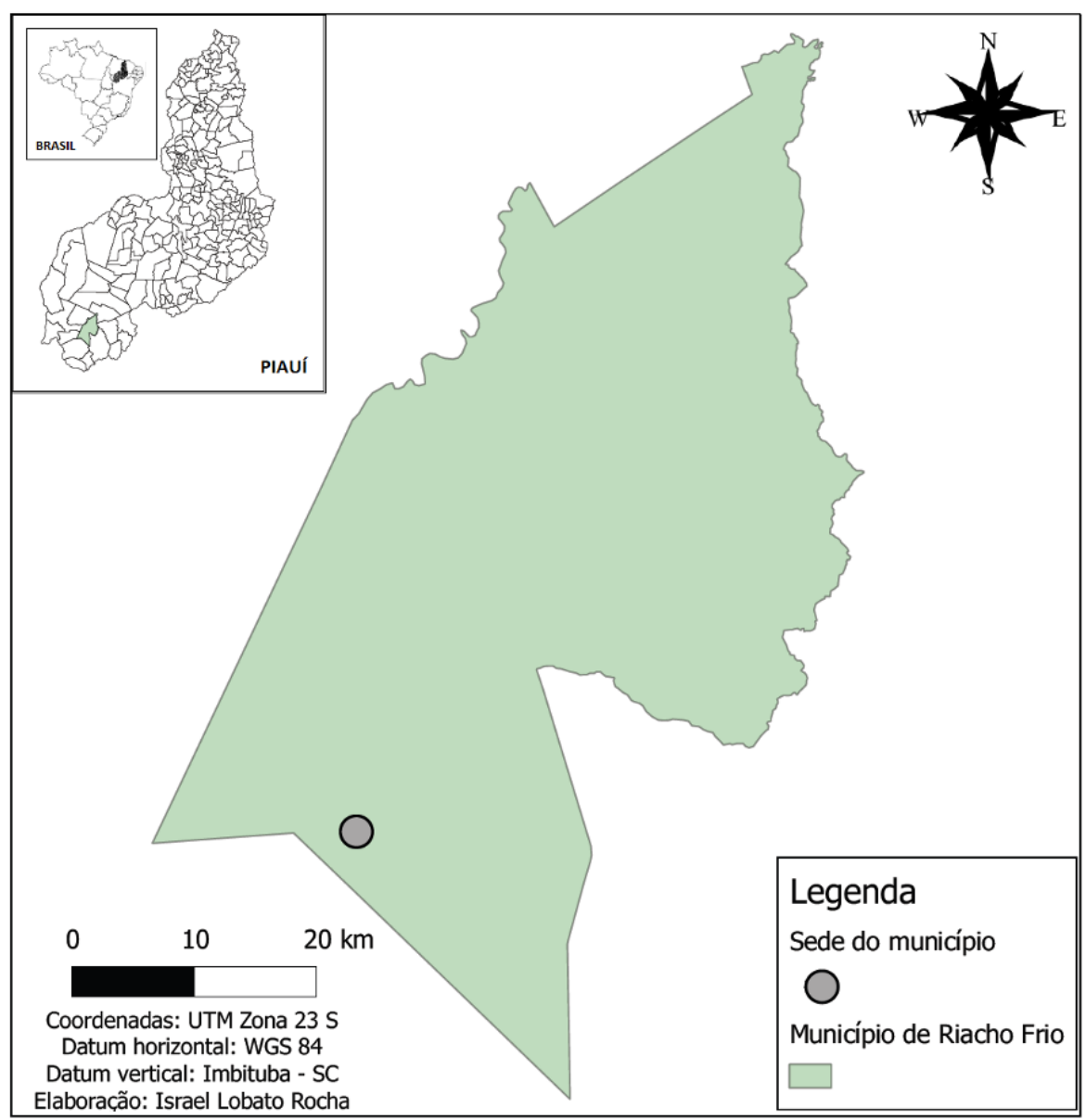

Figura 1 - Localização do município de Riacho Frio- PI. Fonte: Rocha et al., 2013.

\subsection{Aspectos metodológicos}

Para execução deste trabalho foi feito um levantamento de campo, com visita no local, utilizando câmera fotográfica, GPS, material de anotações para identificação dos dispositivos do 
sistema de drenagem analisando os possíveis problemas relacionados aos mesmos. Durante o estudo foi realizada também uma pesquisa bibliográfica em livros, artigos e dissertações em relação ao tema estudado.

Além disso, foi utilizado o software Quantum GIS 2.4.0, Sistema de Informação Geográfica para confecção do mapa que mostra a localização municipal e os elementos pertencentes a drenagem urbana do município estudado.

\section{RESULTADOS E DISCUSSÃO}

Após o levantamento de campo foi possível identificar que o município de Riacho Frio possui deficiência na quantidade e condições sanitárias dos dispositivos de drenagem, pois em toda a cidade apenas 2 ruas a Antônio Mascarenhas e Rua da Matriz possuem bocas-de-lobo e galerias de águas pluviais. Foram contabilizadas 2 galerias de águas pluviais, 7 bocas-de-lobo, sendo 5 classificadas como de guia e 2 de grelha (Figura 2).

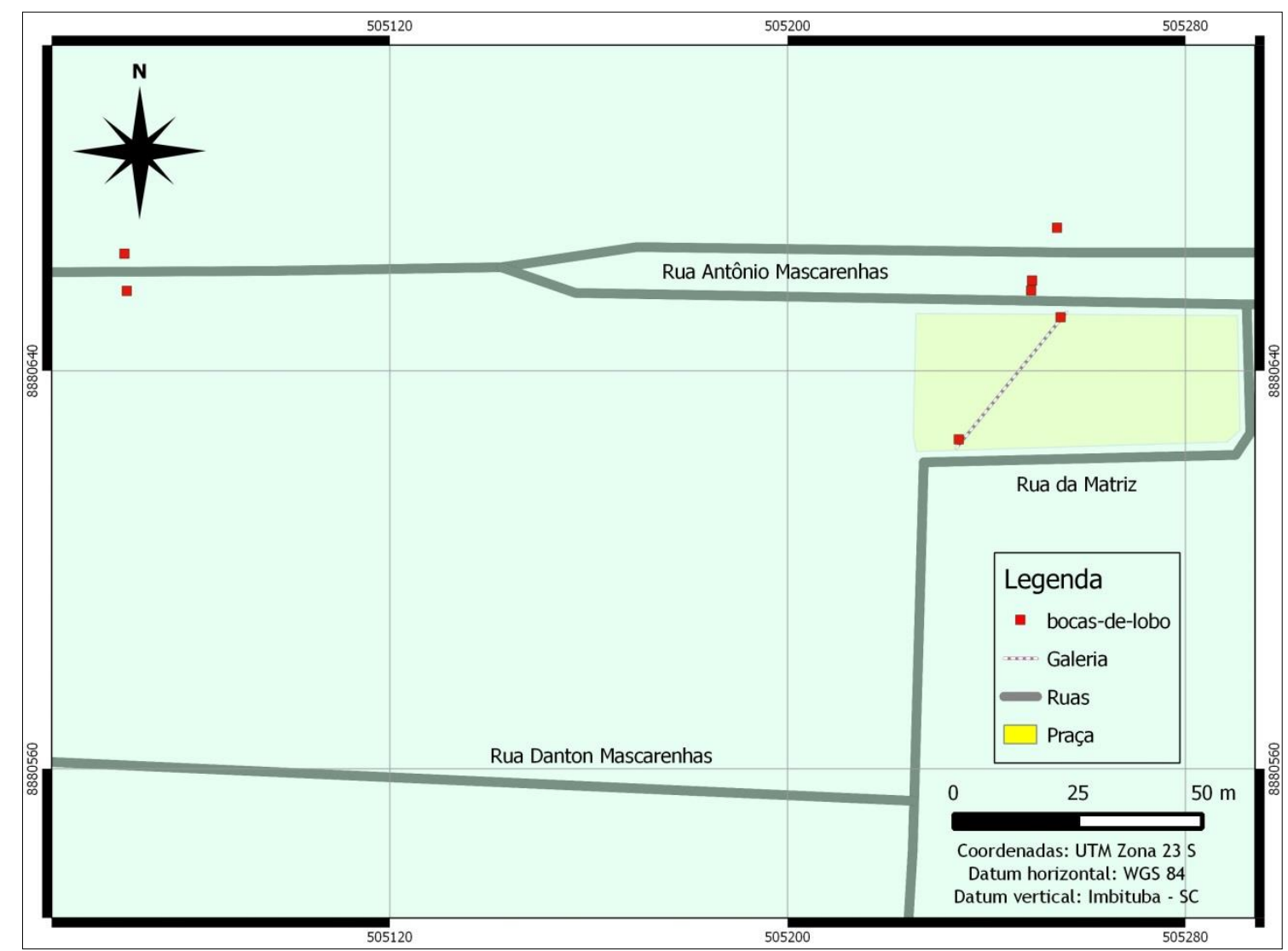

Figura 2 - Elementos da drenagem urbana de Riacho Frio - PI. Fonte: Rocha, 2015.

Constatou também, a presença de resíduos nas galerias e bocas-de-lobo podendo ocorrer à obstrução e comprometer o funcionamento das mesmas (Figura 3). 


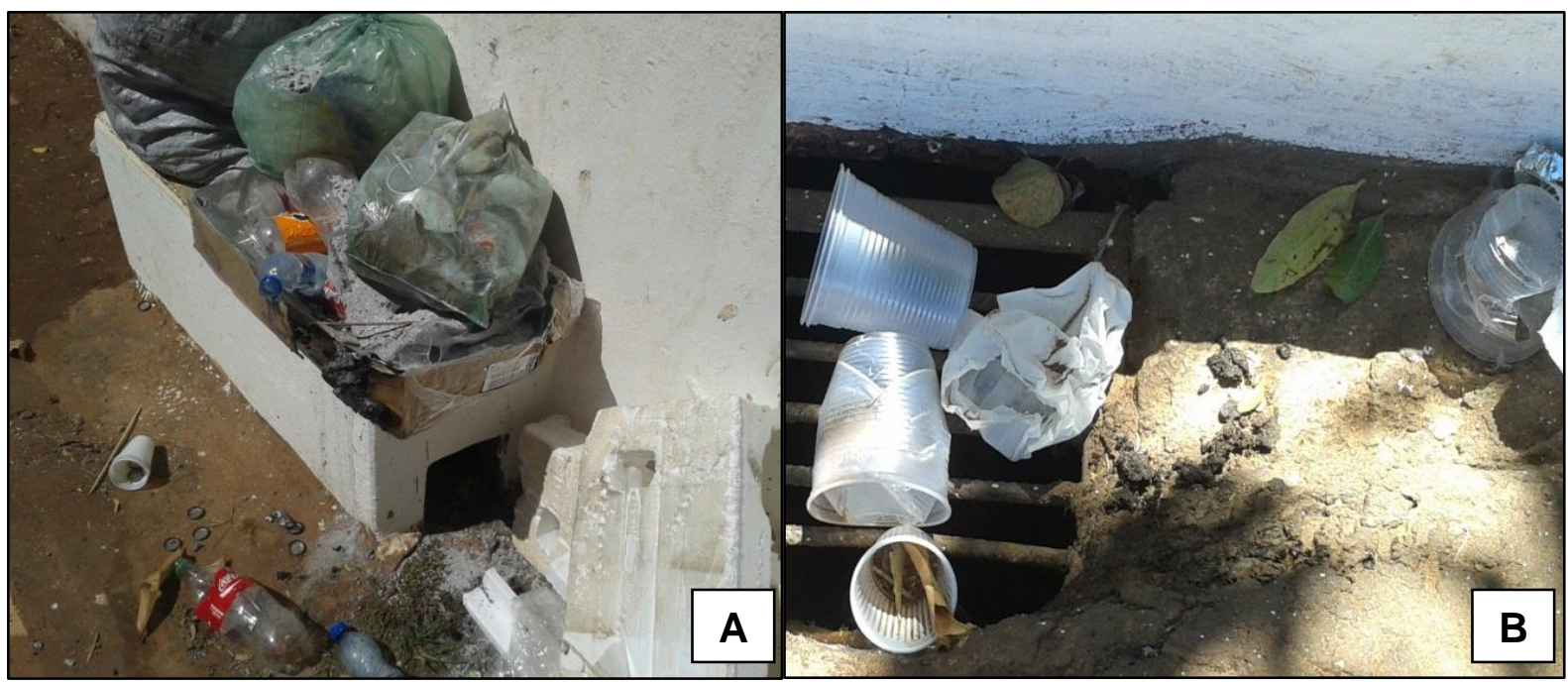

Figura 3 - Boca-de-lobo com disposição irregular de lixo (A). Boca-de-lobo com grelha (B). Fonte: pesquisa de campo, 2015.

Santos (007) argumenta que a limpeza das bocas-de-lobo é fundamental para manter o funcionamento correto do sistema de micro drenagem urbano. Afirma ainda que essa sujeira poderá tornar a boca-de-lobo inoperante durante as chuvas, o que acarretara no alagamento das ruas.

Uma solução para tal problema seria programas de educação ambiental que visem à sensibilização da população de manter as bocas-de-lobo limpas e assim evitar danos à saúde e ao meio ambiente.

Foi observado o lançamento de efluentes na rede de drenagem, prejudicando o funcionamento do sistema, bem como problemas de saúde para a população com a presença de insetos e vetores de doenças. Motivo do lançamento pode ser explicado pela falta de tratamento de esgoto e conhecimento da população (Figura 4).

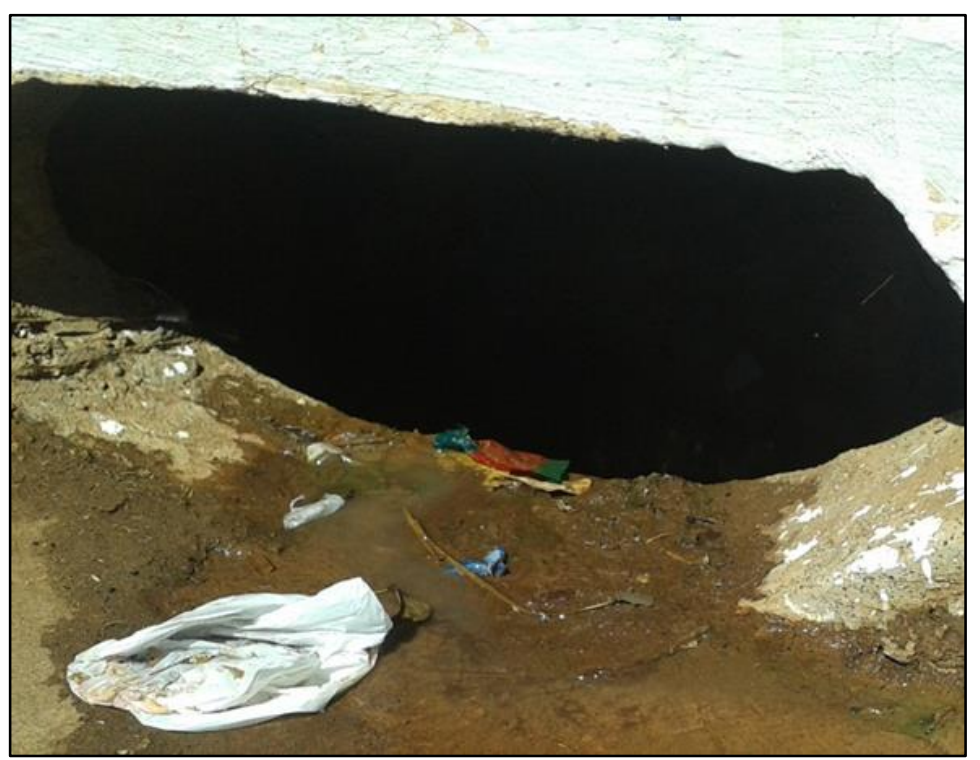

Figura 4 - Lançamento de efluentes domésticos na drenagem. Fonte: pesquisa de campo, 2015. 
A figura 5 mostra a única boca-de-lobo encontrada na Rua da Matriz, o que revela uma deficiência no sistema de drenagem necessitando de um número maior deste dispositivo. É a boca-de-lobo de guia, que se encontra em um estado de conservação danificada devido ao acúmulo de lixo.

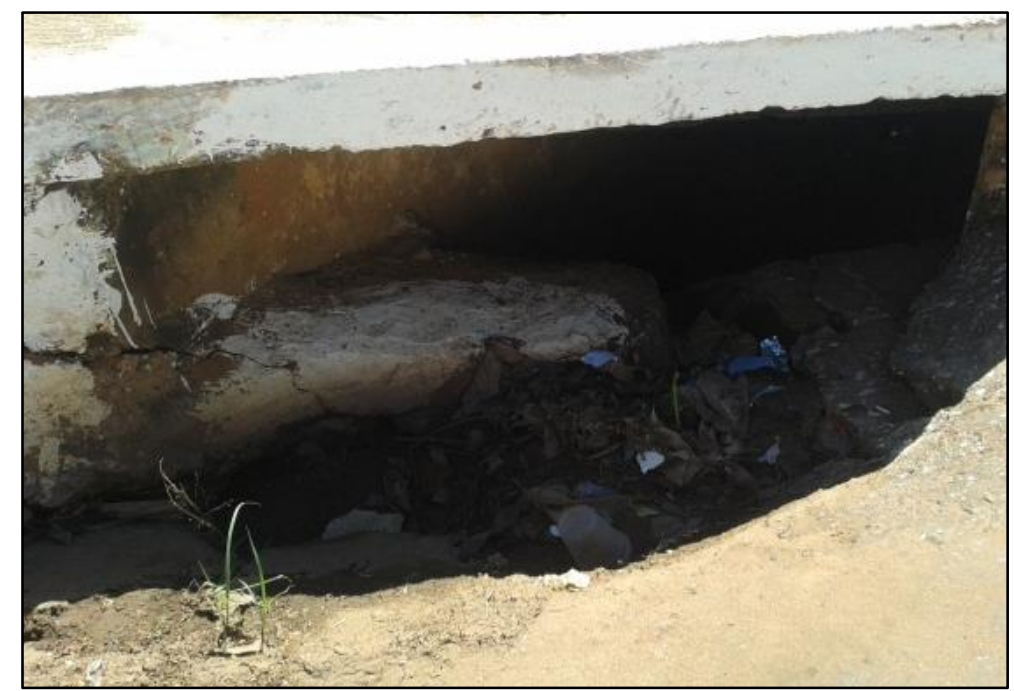

Figura 5 - Boca-de-lobo danificada. Fonte: pesquisa de campo, 2015.

Em relação à disposição das bocas-de-lobo, não foi encontrada nenhuma em lugar impróprio, ou seja, colocadas nas esquinas. Uma das recomendações para localização das bocasde-lobo segundo o Manual de Drenagem urbana (2002) é que a melhor solução para a instalação de bocas-de-lobo é que esta seja feita em pontos pouco a montante de cada faixa de cruzamento usada pelos pedestres, junto às esquinas.

Apesar de algumas das bocas-de-lobo apresentar condições danificadas, foram identificadas também algumas em estado de conservação (Figura 6).

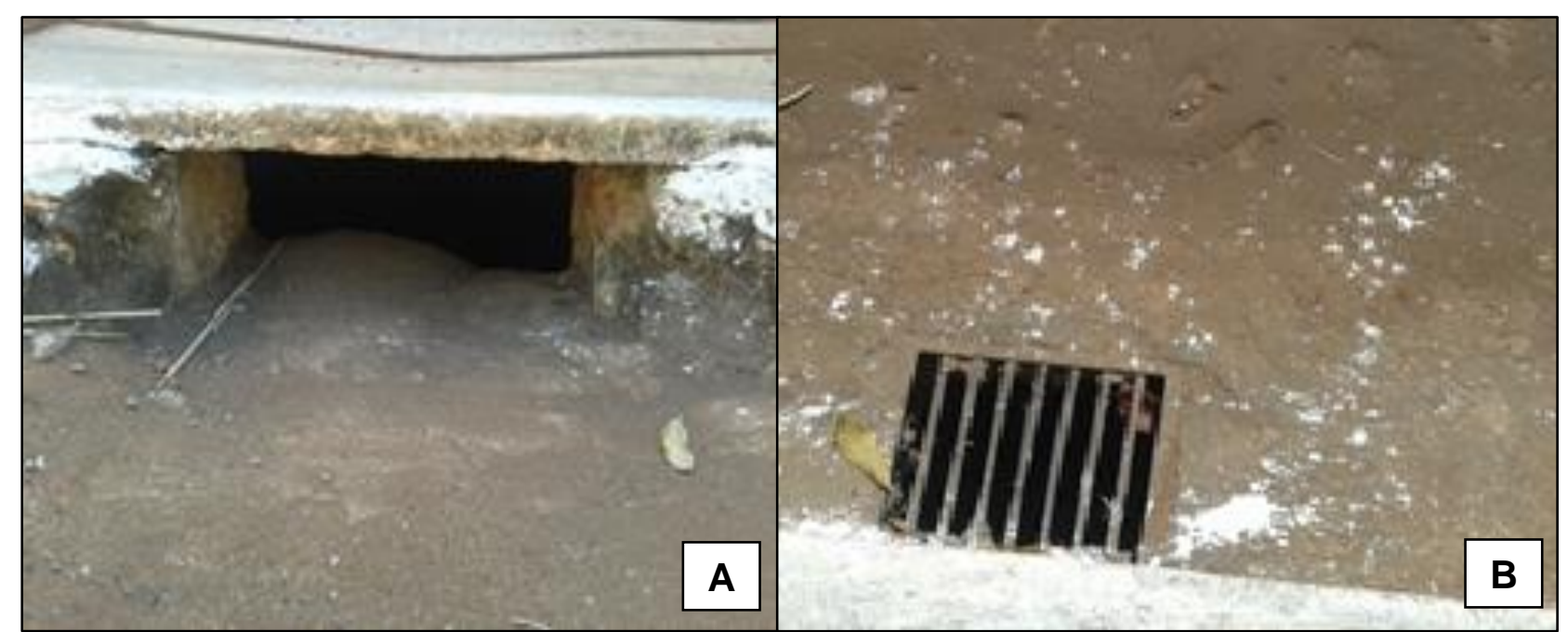

Figura 6 - Bocas-de-lobo conservadas. Fonte: pesquisa de campo, 2015.

\section{CONSIDERAÇÕES FINAIS}


A partir das informações coletadas foi possível observar que o município de Riacho Frio possui um sistema de drenagem urbana precário, apresentando deficiência na quantidade e condições sanitárias dos dispositivos, podendo ocorrer possíveis inundações e alagamento, gerando problemas para a população e para o meio ambiente.

Sendo assim, para amenizar estes problemas é necessária a utilização de medidas de controle estruturais como a construção de pavimentos permeáveis para aumentar a infiltração da precipitação, a inserção de dispositivos de drenagem, bem como programas de educação ambiental para conscientizar a população da importância de manter o sistema de drenagem sempre limpo.

\section{REFERÊNCIAS}

INSTITUTO BRASILEIRO DE GEOGRAFIA E ESTATÍSTICAS (IBGE). Sinopse do Censo demográfico 2010: municípios do Piauí. Disponível em: www.ibge.gov.br/home/estatística/população/censo2010/tabelas pdf/Piauí.pdf. Acesso em: 27 jul.2015.

PARANÁ. Secretaria de Estado do Meio Ambiente e Recursos Hídricos. Manual de Drenagem urbana Região Metropolitana de Curitiba- PR, VERSÃO 1.0. Curitiba, 2002.

ROCHA, I. L; et al. Identificação das estruturas de macrodrenagem do município de Riacho Frio - PI. In: IX Congresso Norte Nordeste de Pesquisa e Inovação (CONNEPI). Anais... São Luís, 2014.

SANTOS, R. F. Vulnerabilidade Ambiental. Brasília: MMA, 2007.

SÃO PAULO (CIDADE). Secretaria Municipal de Desenvolvimento Urbano. Manual de drenagem e manejo de águas pluviais: gerenciamento do sistema de drenagem urbana. São Paulo: SMDU, 2012.

TUCCI, C. E. M. Gestão de Águas Pluviais Urbanas. Brasília: Ministério das Cidades/Global Water Partnership/Wolrd Bank/Unesco, 2005. 